\title{
Website quality for SME wineries: Measurement insights
}

By: Bonnie Canziani and Dianne H. B. Welsh.

Canziani, B., \& Welsh, D.H.B. (2016). Website quality for SME wineries: Measurement insights. Journal of Hospitality and Tourism Technology, 7(3), 266-280.

Made available courtesy of Emerald: http://dx.doi.org/10.1108/JHTT-02-2016-0009

****) Emerald. Reprinted with permission. No further reproduction is authorized without written permission from Emerald. This version of the document is not the version of record. Figures and/or pictures may be missing from this format of the document. ***

\section{Abstract:}

\section{Purpose}

The study aims to offer a general review of website evaluation, with particular application to the winery tourism field. Automated website evaluation is explored as a complementary tool in the evaluation of small and medium enterprise (SME) winery websites.

\section{Design/methodology/approach}

The study adopted a mixed-method investigation including a critical review of winery website evaluation literature and analysis of winery website scores generated through a free service of a commercial automated evaluation scoring system.

\section{Findings}

No standards currently exist for winery website evaluation metrics and current evaluation processes suffer from human rater bias. An automated evaluation scoring system used in the study was able to discriminate between a sample of known best practice websites and other independently formed samples representing average wineries in the USA and in North Carolina.

\section{Research limitations/implications}

Wineries and other small business tourism firms can benefit by incorporating automated website evaluation and benchmarking into their internet strategies. Reported human rater limitations noted in manual evaluation may be minimized using automated rating technology. Automated evaluation system metrics tend to be updated more frequently and offer better alignment with trending consumer expectations for website design.

\section{Originality/value}


The current study used an automated website quality evaluation tool that serves to move winery website design efforts forward and supports the goals of reputation management for tourism businesses relying on internet marketing.

Keywords: Evaluation | Tourism | Quality | Website | Internet | Winery

\section{Article:}

\section{Introduction}

Business websites elicit a mix of multisource impressions and reactions from diverse stakeholders. More specifically, a tourism operator's website resides in the internet space and can be accessed by users who both interact with the site and react to the quality of the site. The quality of the website is a factor that contributes to reputation; much as an operator's physical facility is assessed within a geographic landscape.

Key stakeholders include operators themselves, who are trying to control external perceptions of the business. Next are visitors, who will make critical impression and consumption decisions based on website content and services (Wiseman and Ellig, 2004). Third-party government agencies and professional associations frequently authenticate tourism businesses in their regions. They can, for example, regulate which tourism websites are linked into their portal or central network. Web designers influence websites when they compete for projects and design awards (Simmons et al., 2011). Lastly, a tourism website is central to employees' perceptions of company strategy, market status and how the business fits into the greater tourism destination.

Website evaluation is a natural extension of reputation management for tourism businesses. This study is predicated on the increased importance of the website as a tourism communication tool driving reputation both in terms of multichannel marketing and stakeholder responsiveness.

However, research, to date, is spotty, and there is little consensus about the website evaluation process, particularly with respect to ensuring rater competency. In fact, rater types vary widely across existing studies, including end users (Pang et al., 2009), Web development or usability professionals (Korgaonkar et al., 2009) and student evaluators or academic researchers (Dragulanescu, 2002). Moreover, website evaluation techniques being used are reported as problematic because of biases in human judgment. Emerging evidence points to the use of automated website evaluation as a tactic to reduce the degree of rater error in website evaluation. This paper explores the use of automated Web evaluation as a feasible practice for assessing winery website quality.

Wineries are a high-value tourism sector, yet tend to be family run or small in size, as well as geographically isolated; they are highly dependent on the internet to increase visibility and drive sales and reputation (Canziani and Byrd, 2014). The study has meaning for any tourism business where bricks-and-mortar facilities are difficult to engage with on a regular basis. The study uses a free automated website rating system to collect discrete and global measures of winery websites. 


\section{Literature review}

\subsection{Defining website quality and website evaluation}

Website quality can generally be defined as conformance to specified expectations of stakeholders. Various steps for website evaluation have been suggested (Olsina et al., 2000; Rocha, 2012), which are abridged as follows:

\subsubsection{Step 1: verify that the organization exists in the relevant domain.}

The domain selected, i.e. .edu, gov or .com, must fit the organization hosting the website. The site domain .com, for example, suggests an organization within the commercial sector. There is accepted variability in website design across domain sectors (Simmons et al., 2011), yet the expectation in this paper is that winery operators compete under the .com umbrella, as it signals commercial activity.

\subsubsection{Step 2: apply rational criteria to website evaluation.}

Website design and concomitant evaluation are criteria-driven; criteria and methods for website evaluation evolved over time because of technological advances and recognition of societal needs (Saha and Grover, 2011, p.15). Website design has advanced across five sequential themes depicted in Figure 1: usability, information/content, interactivity (Web 2.0), mobility/integration and more recently the semantic intelligence promised by Web 3.0. These five stages are not discrete constructs but rather indicate evolving foci over the history of website and ecommerce development.

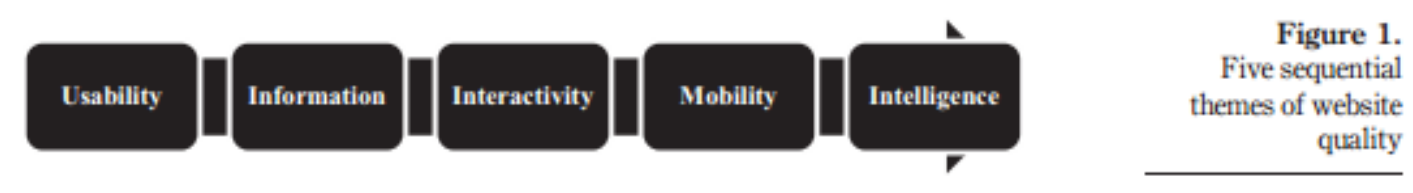

Usability dominated much of the earlier Web development literature (Chen et al., 2009; Selz and Schubert, 1998; Srivihok, 2000). Nielsen (2000) related usability to the quality of the technology interface between company and users. The International Organization for Standardization explicitly recognizes three dimensions of usability: efficiency (the level of resource consumed in performing tasks); effectiveness (the ability of users to complete tasks using the technology and the quality of output of those tasks) and satisfaction (users' subjective satisfaction with using the technology) (ISO 9241-11, 1998).

Usability has been linked to the subsequent success of ecommerce (Nielsen, 2000; Shneidermann, 1998). Palmer (2002) reported that five usability factors (download delay, navigability, content, interactivity and responsiveness) positively correlated with consumers' frequency of use, likelihood of return and user satisfaction. From usability work, information quality, i.e. type and display of content, was spun off from system quality, i.e. site design factors that are more technical in nature (Heldal et al., 2004; Miranda and Bañegil, 2004; Rabin, 
2001; Robbins and Stylianou, 2003). During this period, a majority of firms explored moving catalogs online and expanding shopping cart and search engine functionality.

The third discrete focus in website design to arise was interactivity, spurred by Web 2.0 innovations (Auger, 2005; Bland, 2009; Simon, 2010); consumers could now expect to respond to businesses by using the website itself as a two-way communication system. Innovations related to interactivity thinking included increased accessibility for users (Power et al., 2009) and the deployment of user-generated content, i.e. comments and blog entries. The next design theme, mobile readiness of websites, refers to supporting the use of smaller devices capable of accessing the internet, such as phones and tablets (LoPresti et al., 2014). Lastly, the advent of Web 3.0 promises search capabilities that simulate semantically natural conversation linking the user into a vast global intelligence network.

Changes in technology are not unduly disruptive in terms of designing tourism websites, as prior criteria continue to be mandatory for website design even while new foci and criteria come into play (Pearrow, 2000). However, small and medium enterprise (SME) tourism businesses tend to have steeper learning curves and longer implementation timeframes because of restricted time and resources for ecommerce development and technology adoptions.

\subsubsection{Step 3: pursue reliable global measures of website quality.}

A single website quality score is advantageous, as it can be more easily used for comparing oneself to industry standards and competitor websites. For example, Elliot (2002) introduced a system where specific features of a website are scored and an overall quality mark is calculated from the discrete metrics and used to rank the website compared to other sites. Some researchers have adapted a service quality framework to website evaluation, as in SITEQUAL (Yoo and Donthu, 2001); eQual (Barnes and Vidgen, 2005); E-S-QUAL (Parasuraman et al., 2005); ESEQUAL (Petre et al., 2006); WebQual (Loiacono et al., 2007); and NetQual (Bressolles and Durrieu, 2010).

\subsection{The virtues of automated website evaluation}

The extant literature has concluded that, at a minimum, a website evaluation method needs to provide trustworthy guidance to firms. Stevens and Burns (2005, p. 73) suggested that "technical content [in manual website assessments] was not worth reporting possibly due to the technical nature of a website being harder to observe without significant programming ability". They call for an evaluation approach that actively manages the role of the rater and attempts to reduce rater error.

Palmer (2002), an early adopter of automated Web checking procedures, believed these may be cost-effective and viable tools either to complement or in the absence of reliable raters. Other advantages of automated tools include reduction of rater fatigue and objectivity and independence from local circumstances or bias (Kincl and Štrach, 2013). Ivory and Hearst 2001, p. 471) summarized the advantages of automation over non-automated evaluation as follows: reducing evaluation costs, increasing consistency of errors uncovered, predicting time and error costs across an entire website, reducing the need for expert evaluators, increasing the coverage of 
evaluated features, supporting comparisons between alternative designs and incorporating evaluation within the design phase of website construction. Automated evaluation methods are effective from a threefold perspective of being:

- useful in producing relevant results for stakeholders;

- viable in terms of moderate resource use; and

- consistent across multiple implementations of the tool (Brajnik, 2004).

According to Ford et al. (2012) and Vaucher et al. (2013), automatic website checking tools have become widely deployed in many business sectors and can be used to inspect numerous aspects of website construction and usability, including source code, functioning Web page attributes and content, usage statistics, server performance and search engine positioning.

Based on the aforementioned discussion, research is merited on how to better evaluate tourism website design, particularly for small businesses that depend on websites as their number one outreach and marketing tool. Study research goals are to increase the literature in this area by piloting an automated assessment of winery websites. Wineries clearly represent the small tourism business sector and are growing in numbers across many rural sectors of the world.

\subsection{Background on the winery sector}

A majority of wineries are small- to medium-sized operations (SMEs), which forces wineries to be cautious in spending on marketing and related technology. Wineries do not have ready streams of cash flow to meet the burden of technical license fees or to support specialized technical staff to manage websites and social media strategies. Thus, websites of SME wineries tend to evolve over time, adding increased functionality in phases as funds permit (Simmons et al., 2008).

Winery tourists are highly educated, technology-literate and motivated to acquire detailed product knowledge and information (Houghton, 2008), leading wineries to allocate funding to website design. In addition, social media is increasingly being incorporated into site design (Alonso et al., 2013). Websites are particularly important in attracting specific audiences, i.e. wine club members, younger consumers and non-local tourists, who tend to generate word-ofmouth reputational intelligence and contribute authentic website content through blogging and testimonials. Websites further enable wineries to use interactive Web 2.0 technologies to embellish their image and brand, e.g. virtual winery tours, story-telling and educational videos, virtual wine tasting and social media networking (Thach, 2009).

\subsection{Background on winery website evaluation}

A review of the winery tourism literature revealed only 24 studies relevant to winery website quality (Begalli et al., 2009; Bernet and Stricker, 2001; Bruwer and Wood, 2005; Davidson, 2009; Farshid et al., 2012; Janes, 2010; Mills et al., 2012; Murphy et al., 2005; Notta and Vlachvei, 2013; Nowak and Newton, 2008; Quinton and Harridge-March, 2006; Reyneke et al., 2011; Sellitto et al., 2003; Taylor et al., 2010). The limited reference list is likely because of the present focus on winery website quality rather than on ecommerce in general. 
No standards currently exist for winery website evaluation metrics; the number of different site metrics/items evaluated ranged from 4 to 95 across the 24 articles. Almost one half of the studies (11) used simple presence ratings to score website features, i.e. being "there" or "not there". Only 3 of the 11 studies using presence ratings (Velikova et al., 2011; Yuan et al., 2004; Zhu et $a l ., 2009)$ explicitly stated that the researchers calculated global website ratings from the "yes/no" metrics. Nine of the 24 studies used either Likert-type scales or some other more complex scoring device to assess individual feature quality and compute global measures. Types of raters reviewing winery websites in the literature ranged across academic researchers browsing selected sample winery websites (12); consumer groups testing websites (5); and use of automated evaluation applications available for purchase or as free assessment services (4). The use of identified experts from the Web development field seemed to be minimal, although one study (Petre et al., 2006) reported supplementing academic rater evaluations with usability consultants in a second phase of their study.

\subsection{Validating Website Grader ${ }^{\circledR}$ in the winery context}

Validating an automated tool in the context of winery websites is a key step in understanding the usefulness of such tools for the industry. One such tool is the Website Grader@ by Hubspot, a marketing and sales software company; their free service supplies the following four subtotal metrics as well as a global evaluation score from 0 to 100:

1. Performance (of 30 points): Examining site's page size, requests, speed and more.

2. Mobile Readiness (of 30 points): Checking to see if website is mobile-friendly in terms of responsiveness and viewport settings.

3. Search engine optimization (SEO) (of 30 points): Determining if website is easy to find by both humans and bots. This determination will take factors like page titles and metadescriptions into consideration.

4. Security (of 10 points): Looking for things like an SSL certificate as a way to prove to visitors that the site is both authentic and safe for contact information submissions (Shah, 2015).

It is worth noting that, with respect to the evolution of website design depicted in Figure 1 (usability, information content, interactivity, mobility and intelligence), this tool concentrates heavily on usability with some attention to mobility issues. Effectiveness of marketing content and dynamic features of Web 2.0 and 3.0 are not evaluated by the tool. General automated tools tend to focus on technical aspects because of these being relevant regardless of industry sector and being more difficult for non-technical business professionals to evaluate on their own.

Evaluation is generally comparative in nature, as the tool rates a single winery's website or a group of websites against a desirable standard score or against competitor wineries. In this study, the evaluation of North Carolina websites was part of a greater winery marketing investigation effort. Nonetheless, the study helps exemplify how a scoring tool might help a "client" address the quality of its websites. A valid scoring tool should be able to discriminate between best designs and average designs. Because best-practice wineries are described as such on the basis of highly ranked design features, one expects a set of best practice websites to exhibit higher 
evaluation scores when compared to a sample of randomly selected North Carolina winery websites. Such a disparity is not expected between a random set of North Carolina websites and a random set of US websites, as the design ranking was not a sampling factor in the latter case.

Given this study's focus on supplementing human rater evaluation of websites with automated evaluation methods, the following hypotheses were designed to validate the global scores produced by the deployed webcrawler:

\section{Hypotheses}

H1.The mean performance of a random sample of North Carolina winery websites would be significantly lower than the mean performance of a set of best practice winery websites. $H 2$. The mean performance of North Carolina winery websites would not differ significantly from the mean performance of a random sample of winery websites from outside the state.

\section{Research methodology}

\subsection{Sampling design}

The initial sampling frame constituted the URLs of 140 wineries in the State of North Carolina listed on the state tourism portal. The NC sample comprised a random sample of 72 usable websites, i.e. wineries in the data set had a clear, independent Web presence, a unique domain and the website's sub-pages were accessible to the webcrawler. A benchmark comparison set of 20 top US winery website URLs identified from an independent blog source, i.e. The Winery Web Site Report (Duffy, 2006). Table I lists the elements reportedly used by The Winery Web Site Report with best-practice wineries attaining a minimum of 75 points out of 100 compared to a mean and median of 48 points across 2,000-plus winery sites.

A control sample of 65 website URLs was composed by randomly sampling publicly available government or state trade association winery lists in the following states: California (15), New York (14), Colorado (11), Virginia (15) and Oregon (10).

\subsection{Data collection using the automated webcrawler scoring system}

Website quality was assessed in this study by using the Website Grader ${ }^{\circledR}$ by Hubspot (Shah, 2015). After one inputs the winery URL, the webcrawler begins at a winery's homepage. For a hypothetical NC Vineyards, the process starts at www.NCVineyards.com/ and accesses subpages to generate global scores of 1 to 100 as well as scores for performance, SEO, security and mobility. Table IIprovides the breakdown of evaluated components and weightings that underlie these four rated dimensions (Shah, 2015).

The metrics deployed in both Tables I and II are based on standards used to develop secure and usable electronic commerce websites and also conform to metrics identified in previous studies cited in this paper, practitioner journals and the researchers' experience in website usability consulting. Overlap between the original scoring of The Winery Website Report and the Website 
Grader $^{\circledR}$ exists, in that approximately half or more of measured items relate to the usability dimension of website quality.

\begin{tabular}{|c|c|c|}
\hline \multirow{3}{*}{$\begin{array}{l}\underset{7,3}{\mathrm{HT}} \\
7,3\end{array}$} & & \\
\hline & \multicolumn{2}{|c|}{ Site evaluation score } \\
\hline & Rating element & Maximum score \\
\hline \multirow{5}{*}{272} & Branding/identification & 5 \\
\hline & Compatibility & 5 \\
\hline & Contact information & 3 \\
\hline & Domain name & 3 \\
\hline & Freshness & 4 \\
\hline \multirow{22}{*}{$\begin{array}{l}\text { Table I. } \\
\text { Best-practice } \\
\text { wineries scoring } \\
\text { method }\end{array}$} & Information: current releases & 6 \\
\hline & Information: past releases & 3 \\
\hline & Media media kit & 4 \\
\hline & Navigation: buyers & 5 \\
\hline & Navigation: browsers & 5 \\
\hline & Navigation: trade & 4 \\
\hline & Navigation: media & 3 \\
\hline & Navigation: consistency & 5 \\
\hline & Navigation: site map & 5 \\
\hline & Navigation: link to home page & 5 \\
\hline & Newsletter & 1 \\
\hline & Obstacle-free & 5 \\
\hline & Personalization & 4 \\
\hline & RSS & 4 \\
\hline & Responsiveness and availability & 1 \\
\hline & Search rank & 5 \\
\hline & Shipping information & 5 \\
\hline & Site search & 1 \\
\hline & Trade: marketing materials & 4 \\
\hline & Visual appeal & 5 \\
\hline & Overall score & 100 \\
\hline & \multicolumn{2}{|l|}{ Source: Duffy (2006) } \\
\hline
\end{tabular}

\subsection{Statistical analysis}

SPSS Version 23 was used to test hypotheses. To test $H 1$, the study sample was compared to 20 top US winery websites. Second, in a test of $H 2$, the study sample was compared to a control sample of 65 US winery websites.

\section{Results}

\subsection{Validating an automated scoring system against best practice and control samples}

$H 1$ and $H 2$ were focused on validating the usefulness of the automated tool in the context of wineries using NC wineries as a hypothetical "client" and comparing their results to best practice wineries and to targeted standard scores defined by the tool itself. To assess criterion-related validity $\mathrm{NC}$ wineries were compared against independently ranked best-practice winery websites. Figure 2provides a quick look at the differences in total scores (out of 100 points) of the NC sample $(\bar{x}=55.06)$, the top website groups $(\bar{x}=63.75)$ and a random control sample of US wineries $(\bar{x}=60.27)$. 
Means comparison tests using SPSS Version 23 were used to test the hypotheses. Best-practice wineries had overall higher website quality compared to the NC wineries sample (Table III), with a significant mean difference of 8.69 in the overall website score $(t=-2.198 ; p=0.034)$, providing support for $H 1$. The primary factor that that set apart the best practices was their mobile technology platform which exceeded the average NC winery by 10.04 points.

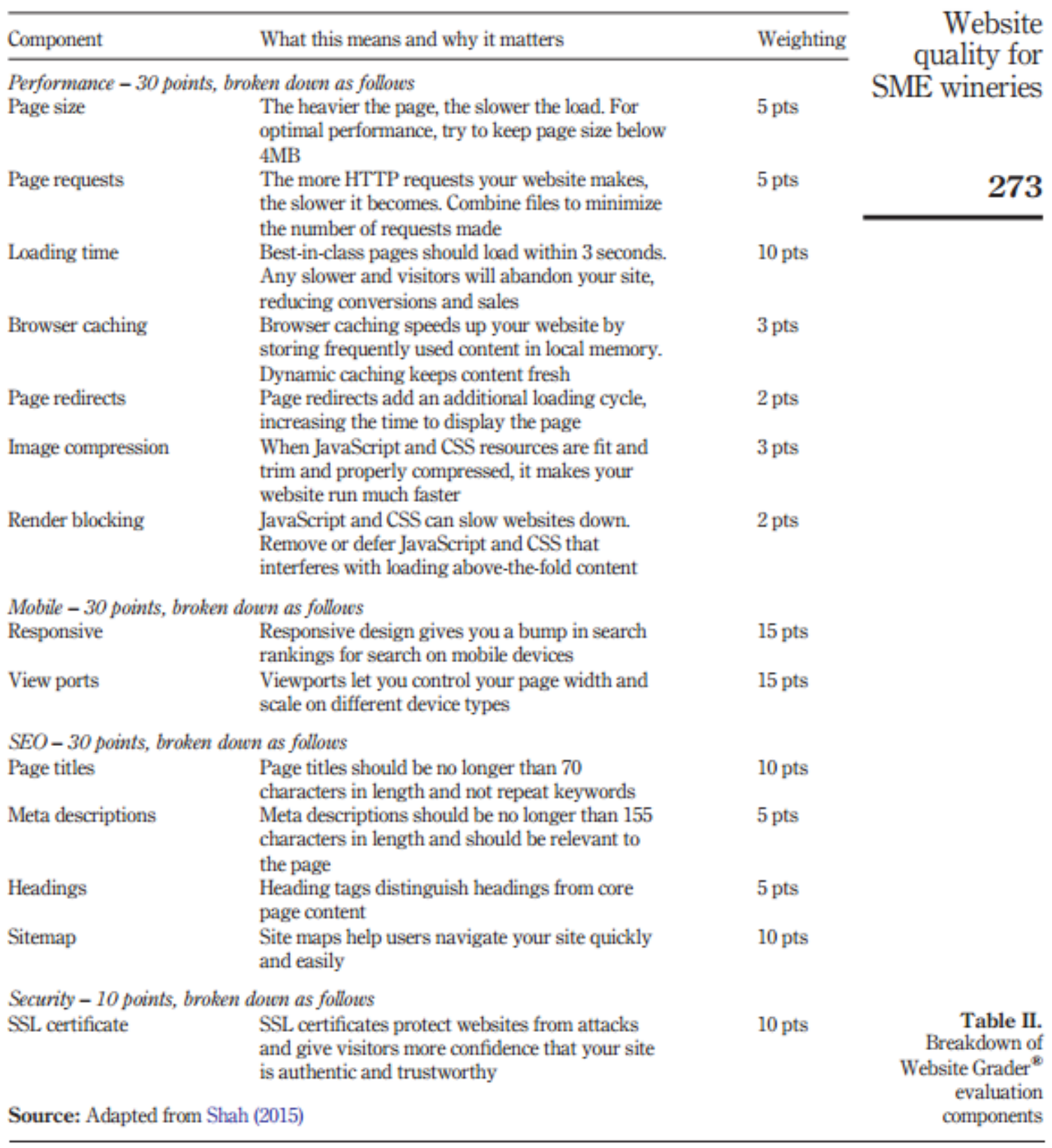

Means comparison tests using SPSS Version 23 were used to test the hypotheses. Best-practice wineries had overall higher website quality compared to the $\mathrm{NC}$ wineries sample (Table III), with a significant mean difference of 8.69 in the overall website score $(t=-2.198 ; p=0.034)$, providing support for $H 1$. The primary factor that that set apart 
The results found in Table IV have us to also accept $H 2$. An average group of NC wineries did not perform differently in overall score performance from a random sample of wineries from other states. Mobile readiness was still observed to be lower in the NC sample.

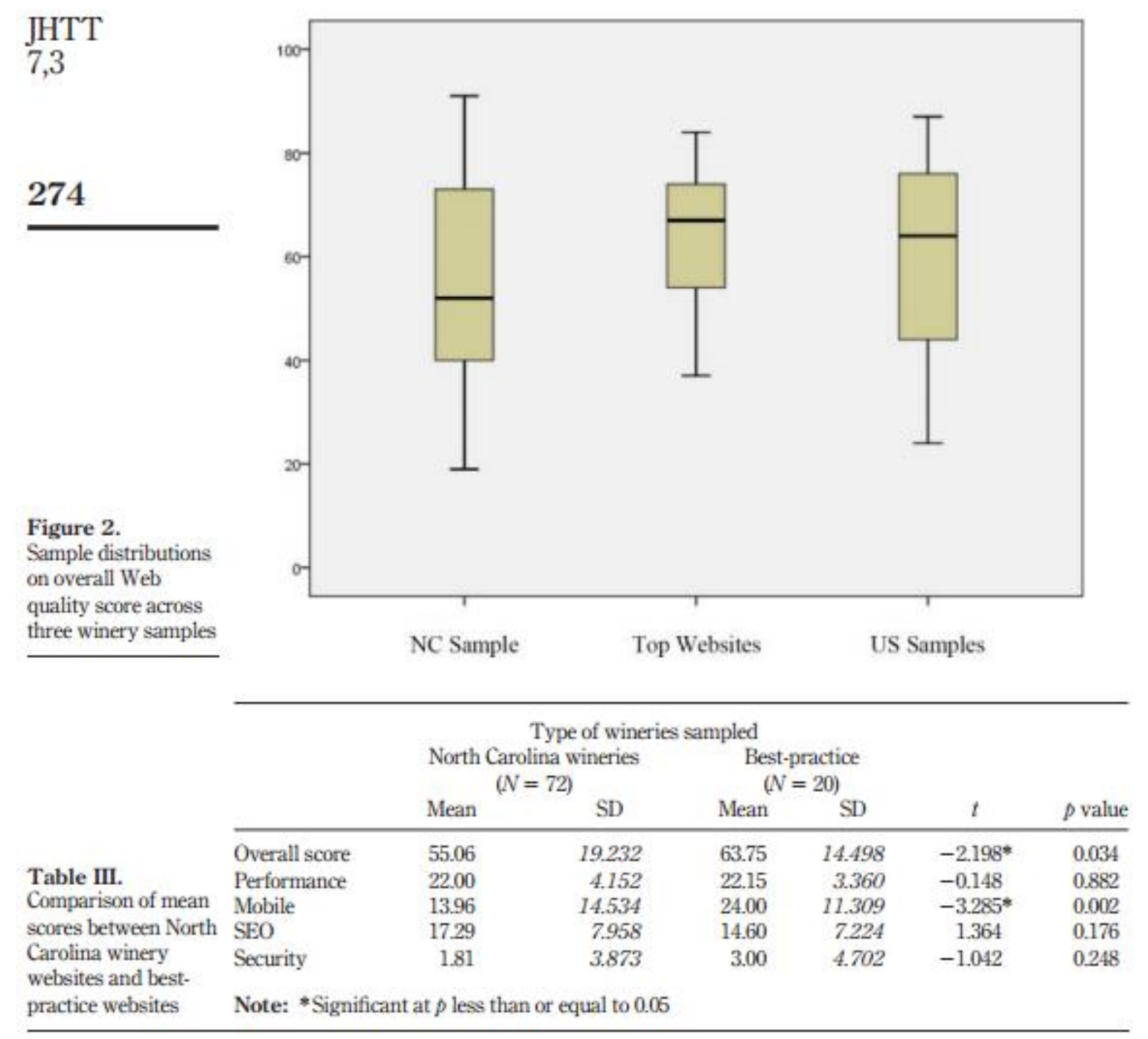

\section{Conclusion}

A review of the literature led to the validation of a free generic automated tool in the context of winery website evaluation. Because no consensus existed in the winery tourism literature regarding a preferred approach to website evaluation, standardized measures were sought that would support the website design trends depicted in Figure 1. One goal was to locate a website evaluation tool that would be useful to SME tourism practitioners, in light of the growing use of internet marketing by many SME wineries which comprise the majority of units in the USA. Also, work reported to date in winery website evaluation showed that human rater bias impacts decisions about website quality. The lack of an acceptable routinized tool for evaluating website 
quality is limiting on the winery field itself, as it does not clarify or balance the foci that are important in website design.

Website Grader $^{\circledR}$ was used with a sample of wineries to collect global and subset measures of winery website quality. A comparison of means indicated that the sample of NC wineries scored lower in website quality than a sample of independently recognized best-practice websites, but did not perform significantly differently overall from a random sample of US winery websites. Findings did indicate a tendency for NC wineries to be less mobile-friendly than other wineries scored in this study, suggesting that the state's wineries were not moving as rapidly in upgrading their websites to adopt latest technologies.

\subsection{Implications for tourism practitioners}

Wineries, like many tourism businesses, have a strong desire to reach expanded audiences, yet many wineries cannot afford to invest blindly in Web designs. The automated webcrawler has several critical features that support benchmarking: multidimensionality in terms of industryrelevant, user-critical and Web expert-defined metrics; rater consistency [being automated]; and scoring complexity in offering both discrete and overall measures. Supported by global and sub-metric measures, Web development staff can use results to refine individual website components. The degree to which usability features and SEO dominate the automated evaluation of websites is clearly a factor in determining the usefulness of automated tools. This study provides evidence that the automated tool can be a valid method for rating both usability and mobile platform support. Given the research in the technical literature, the preference for reducing human rater error through automation, as well as the winery literature's insufficient evidence of recommended evaluation techniques, the use of a tool such as Website Grader ${ }^{\circledR}$ is worth considering.

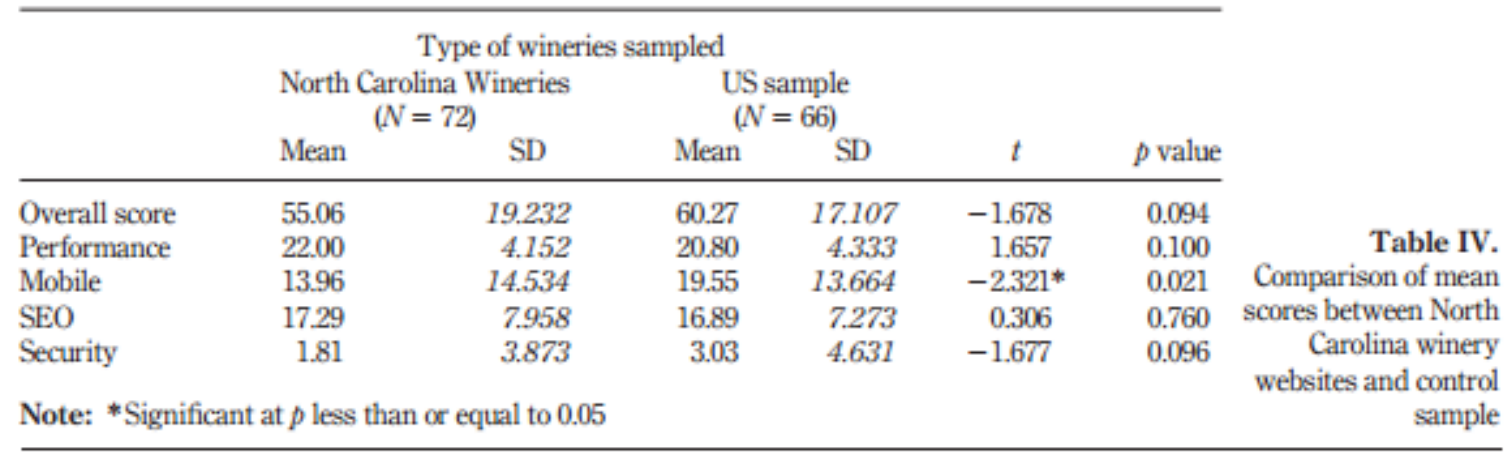

Wineries can also ascertain competitive positions against comparison groups, as seen by the various hypotheses tested in the present study. Thus, at the individual level, the scoring tool provides useful data about how each winery website generally performs and offers insight as to what improvements would be warranted based on review of specific metric scores against targeted standard scores. And, overall scores provide a basis for comparing two or more wineries against each other or a set of wineries against another as in current examinations of North Carolina wineries. 


\subsection{Limitations and future research}

This paper is focused primarily on assessing websites. The study does not assess overall internet strategy of a winery or website impacts on ecommerce outcomes. There were considerable restrictions on information reported from the free service because of the commercial nature of the evaluation tool. Thus, while the validation of the tool for winery websites is satisfactory, the level of detail available for making actual improvements or recommendations was severely limited in a practical sense. Furthermore, the use of a primary sample in North Carolina was dictated by broader research goals focusing on winery tourism within the state. However, no evidence emerged during this study to indicate that using North Carolina as a "client" was in any way inadequate as a pilot test of the automated evaluation tool.

Future research is still required on website design and evaluation. In particular, it is desirable to verify if the automated tool is complete within itself or only complementary to other types of website evaluation. Other foci of website design, such as relevance of content to various users and interactivity (user-generated content and accessibility), demand increased attention in the website evaluation field. Future research can be particularly beneficial as one takes into consideration evolving social media measures available from services such as TripAdvisor, Yelp and Facebook. Also, further research can help define exactly what about automating the evaluation process is better than human judgment, beyond its ability to manage a large set of quality metrics or reducing undesirable levels of human fatigue and increasing rater reliability. Research on the aggregation of metrics into global scores will continue to be an area of interest for all types of tourism website evaluations. Furthermore, future research is needed to expand site benchmarking for wineries and for other tourism subsectors, e.g. tour guides or bed and breakfasts, to support these small businesses that depend on websites for their marketing and promotions. This is particularly true when the business is in a rural district, as many wineries are due to the nature of their business, i.e. agritourism.

\section{References}

1. Alonso, A., Bressan, A., O'Shea, M. and Krajsic, V. (2013), "Website and social media usage: implications for the further development of wine tourism, hospitality, and the wine sector", Tourism Planning and Development, Vol. 10 No. 3, pp. 229-248.

2. Auger, P. (2005), "The impact of interactivity and design sophistication on the performance of commercial websites for small businesses", Journal of Small Business Management, Vol. 43 No. 2, pp. 119-137.

3. Barnes, S. and Vidgen, R. (2005), "The eQual approach to the assessment of e-commerce quality: a longitudinal study of internet bookstores", in Suh, W. (Ed.), Web Engineering: Principles and Techniques, IGI Global, Hershey, PA, pp. 161-181.

4. Begalli, D., Codurri, S. and Gaeta, D. (2009), "Wine and web marketing strategies: the case study of Italian specialty wineries", British Food Journal, Vol. 111 No. 6, pp. 598-619. 
5. Bernet, A. and Stricker, S. (2001), "German wineries on the web: a survey of websites of Mosel-Saar-Ruwer and Pfalz wineries", 75th European Seminar of the EAAE), pp. 1-8, available at: www.wine-economics.de/Research/wineries.PDF

6. Bland, V. (2009), "Website development: avoiding the traps", NZ Business, Vol. 23 No. 1, pp. 52-55.

7. Brajnik, G. (2004), "Comparing accessibility evaluation tools: a method for tool effectiveness", Universal Access in the Information Society, Vol. 3 Nos 3/4, pp. 252-263.

8. Bressolles, G. and Durrieu, F. (2010), "A typology of online buyers for French wine web sites based on electronic service quality dimensions", International Journal of Wine Business Research, Vol. 22 No. 4, pp. 335-348.

9. Bruwer, J. and Wood, G. (2005), "The Australian online wine-buying consumer: motivational and behavioural perspectives", Journal of Wine Research, Vol. 16 No. 3, pp. 193-211.

10. Canziani, B. and Byrd, E. (2014), Strategic Plan North Carolina Wine and Grape Industry (2014-2019): A Taste for Everyone, University of North Carolina Greensboro, Greensboro, NC.

11. Chen, Y., Germain, C.A. and Rorissa, A. (2009), "An analysis of formally published usability and Web usability definitions", Proceedings of the American Society for Information Science and Technology, Vol. 46 No. 1, pp. 1-18.

12. Davidson, R. (2009), "A longitudinal study of Australian winery websites", Asia Pacific Management Review, Vol. 14 No. 4, pp. 379-392.

13. Dragulanescu, N.G. (2002), "Website quality evaluations: criteria and tools", International Information and Library Review, Vol. 34 No. 3, pp. 247-254.

14. Duffy, M. (2006), “The Winery Web Site Report", available at: www.winerywebsitereport.com/index.html

15. Elliot, S. (2002), Electronic Commerce B2C Strategies and Model, John Wiley and Sons, Chichester.

16. Farshid, M., Chan, A. and Nel, D. (2012), "A sweet face man: using Chernoff faces to portray social media wine brand images", International Journal of Wine Business Research, Vol. 24 No. 3, pp. 183-195.

17. Ford, E.W., Huerta, T.R., Schilhavy, R.A.M. and Menachemi, N. (2012), "Effective US health system websites: establishing benchmarks and standards for effective consumer engagement", Journal of Healthcare Management, Vol. 57 No. 1, pp. 47-64. 
18. Heldal, F., Svovold, E. and Foyn, A. (2004), "Success on the Internet: optimizing relationship through the corporate site", International Journal of Information Management, Vol. 24 No. 2, pp. 115-129.

19. Houghton, M. (2008), "Classifying wine festival customers: comparing an inductive typology with Hall's wine tourist classification”, International Journal of Culture, Tourism and Hospitality Research, Vol. 2 No. 1, pp. 67-76.

20. ISO (1998), ISO 9241-11:1998 Ergonomic Requirements for Office Work with Visual Display Terminals (VDTs) - Part 11: Guidance on Usability, ISO, Geneva.

21. Ivory, M. and Hearst, M. (2001), "The state of the art in automating usability evaluation of user interfaces”, ACM Computing Surveys, Vol. 33 No. 4, pp. 470-516.

22. Janes, J. (2010), "Wine sales and the internet market", AALL Spectrum, Vol. 14 No. 9, pp. 22-23, available at: www.aallnet.org/main-menu/Publications/spectrum/Archives/Vol14/pubsp1007/pub-sp1007-wine.pdf (accessed 10 January 2014).

23. Kincl, T. and Štrach, P. (2013), "Cultural differences in online beer marketing: findings from automated attention analysis”, Behaviour and Information Technology, Vol. 32 No. 7, pp. 644654.

24. Korgaonkar, P., O’Leary, B. and Silverblatt, R. (2009), “Critical factors to successful website development: opinions of website designers and developers", International Journal of E-Business Research, Vol. 5 No. 4, pp. 39-54.

25. Loiacono, E.T., Watson, R.T. and Goodhue, D.L. (2007), "WebQual: an instrument for consumer evaluation of web sites", International Journal of Electronic Commerce, Vol. 11 No. 3, pp. 51-87.

26. LoPresti, M., Appelboom, G., Bruyere, O., Reginster, J., Klug, E. and Connolly, E. (2014), "Patient engagement in clinical research through mobile technology", Clinical Practice. Vol. 11 No. 6, pp. 549-551.

27. Mills, A.J., Pitt, L. and Sattari, S. (2012), "Reading between the vines: analyzing the readability of consumer brand wine web sites", International Journal of Wine Business Research, Vol. 24 No. 3, pp. 169-182.

28. Miranda, F.J. and Bañegil, T.M. (2004), “Quantitative evaluation of commercial websites: an empirical study of Spanish firms", International Journal of Information Management, Vol. 24 No. 4, pp. 313-328.

29. Murphy, J., Ho, P. and Chan, C. (2005), “Competitive analyses for marketing electronic wine tourism", International Journal of Wine Marketing, Vol. 17 No. 3, pp. 39-54.

30. Nielsen, J. (2000), Designing Web Usability, New Riders Publishing, Indianapolis, IN. 
31. Notta, O. and Vlachvei, A. (2013), "Web site utilization in SME business strategy: the case of Greek wine SMEs”, World Journal of Social Sciences, Vol. 3 No. 5, pp. 131-141.

32. Nowak, L. and Newton, S. (2008), "Using winery web sites to launch relationships with millennials", International Journal of Wine Business Research, Vol. 20 No. 1, pp. 53-67.

33. Olsina, L., Lafuente, G., Lafuente, G. and Ross, G. (2000), "Using web-site QEM to measure the quality of sites", paper presented at II Workshop de Investigadores en Ciencias de la Computación, pp. 111-113, available at: http://sedici.unlp.edu.ar/bitstream/handle/10915/22155/Documento_completo.pdf?sequence= 1 (accessed 28 September 2015).

34. Palmer, J.W. (2002), "Web site usability, design, and performance metrics", Information Systems Research, Vol. 13 No. 2, pp. 151-167.

35. Pang, M., Suh, W., Kim, J. and Lee, H. (2009), “A benchmarking-based requirement analysis methodology for improving web sites", International Journal of Electronic Commerce, Vol. 13 No. 3, pp. 119-162.

36. Parasuraman, A., Zeithaml, V.A. and Malhotra, A. (2005), "E-S-QUAL: a multiple-item scale for assessing electronic service quality", Journal of Service Research, Vol. 7 No. 3, pp. 213-233.

37. Pearrow, M. (2000), Web Site Usability Handbook, Charles River Media, Rockland, MA.

38. Petre, M., Minocha, S. and Roberts, D. (2006), "Usability beyond the website: an empirically grounded e-commerce evaluation instrument for the total customer experience", Behavior and Information Technology, Vol. 25 No. 2, pp. 189-203.

39. Power, C., Freire, A. and Petrie, H. P. (2009), "Integrating accessibility evaluation into web engineering processes", International Journal of Information Technology and Web Engineering, Vol. 4 No. 4, pp. 54-77.

40. Quinton, S. and Harridge-March, S. (2006), "The interaction of technology in entrepreneurial marketing: an illustrative case from a wine merchant", Strategic Change, Vol. 15 No. 2, pp. 85102.

41. Rabin, S. (2001), "Providing a high-performing commerce site", Information Systems Management, Vol. 18 No. 2, pp. 40-51.

42. Reyneke, M., Pitt, L. and Berthon, P.R. (2011), "Luxury wine brand visibility in social media: an exploratory study", International Journal of Wine Business Research, Vol. 23 No. 1, pp. 21-35. 
43. Robbins, S. and Stylianou, A. (2003), "Global corporate websites: an empirical investigation of content and design", Information and Management, Vol. 40 No. 3, pp. 205-212.

44. Rocha, Á. (2012), "Framework for a global quality evaluation of a website”, Online Information Review, Vol. 36 No. 3, pp. 374-382.

45. Saha, R. and Grover, S. (2011), "Quantitative evaluation of website quality dimension for web 2.0 environment", International Journal of u- and e- Service, Science and Technology, Vol. 4 No. 4 , pp. 15-36.

46. Sellitto, C., Wenn, A. and Burgess, S. (2003), "A review of the web sites of small Australian wineries: motivations, goals and success", Information Technology and Management, Vol. 4 No. 2-3, pp. 215-232.

47. Selz, D. and Schubert, P. (1998), "Web assessment: a model for the evaluation and the assessment of successful electronic commerce applications", Thirty-First Annual Hawaii International Conference on System Sciences, Vol. 4, available at: http://csdl2.computer.org/comp/proceedings/hicss/1998/8242/04/82420222.pdf (accessed 5 August 2005).

48.Shah, D. (2015), "Help create the best Website Grader ever!", available at: https://inbound.org/blog/help-create-the-best-website-grader-ever (accessed 3 May 2016)

49. Shneidermann, B. (1998), Designing the User Interface: Strategies for Effective HumanComputer Interaction, Addison-Wesley, Reading, MA.

50. Simmons, G., Armstrong, G. and Durkin, M. (2008), “A conceptualization of the determinants of small business website adoption”, International Small Business Journal, Vol. 26 No. 3, pp. 351-389.

51. Simmons, G., Armstrong, G. and Durkin, M. (2011), "An exploration of small business website optimization: enablers, influencers and an assessment approach”, International Small Business Journal, Vol. 29 No. 5, pp. 534-561.

52. Simon, F. (2010), "The experiential aspects of online search information for new customers to a website", Canadian Journal of Administrative Sciences, Vol. 27 No. 4, pp. 292-305.

53. Srivihok, A. (2000), An Assessment Tool for Electronic Commerce: End User Evaluation of Web Commerce Sites, Faculty of Science, Kasetsart University, Bangkok.

54. Stevens, N. and Burns, E. (2005), "Website use in the Hawke's Bay wine region of New Zealand”, International Journal of Wine Marketing, Vol. 17 No. 1, pp. 69-83.

55. Taylor, D.C., Parboteeah, D.V. and Snipes, M. (2010), "Winery websites: effectiveness explored", Journal of Business Administration Online, Vol. 9 No. 2, available at: www.atu.edu/business/jbao/Menu/fall2010t.htm (accessed 12 November 2013). 
56. Thach, L. (2009), "Wine 2.0-the next phase of wine marketing? Exploring US winery adoption of wine 2.0 components", Journal of Wine Research, Vol. 20 No. 2, pp. 143-157.

57. Vaucher, S., Moulart, A., Sahraoui, H. and Habra, N. (2013), “Automated evaluation of website navigability: an empirical validation of multilevel quality models", Journal of Software: Evolution and Process, Vol. 25 No. 8, pp. 815-839.

58.Velikova, N., Wilcox, J. and Dodd, T. (2011), "Designing effective winery websites: marketing-oriented versus wine-oriented websites", 6th AWBR International Conference, Bordeaux Management School, 9-10 June.

59. Wiseman, A. and Ellig, J. (2004), "Market and nonmarket barriers to internet wine sales: the case of Virginia", Business and Politics, Vol. 6 No. 2, pp. 1-34.

60. Yoo, B. and Donthu, N. (2001), "Developing a scale to measure the perceived quality of internet shopping sites (SITEQUAL)", Quarterly Journal of Electronic Commerce, Vol. 2 No. 1, pp. 31-47.

61. Yuan, J., Morrison, A.M., Linton, S., Feng, R. and Jeon, S.M. (2004), "Marketing small wineries: an exploratory approach to website evaluation”, Tourism Recreation Research, Vol. 29 No. 3, pp. 15-25.

62. Zhu, Y., Basil, D.Z. and Hunter, M.G. (2009), "The extended website stage model: a study of Canadian winery websites", Canadian Journal of Administrative Services, Vol. 26 No. 4, pp. 286-300. 